Berta Lastarria Cavero

\title{
La Infanzona
}

(Leyenda)

I

ESDE el dia aquel. en el cual Don Rodrigo Aranda circundó a paso lento su repartimiento de tierras, que el Rey su señor tuviera a bien otorgarle en premio de sus servicios. y rompió ramas de árboles y disparó puñados de tierra en distintas direcciones. y desenvainando la espada ordenó a los señores del Cabildo que salieran de su propiedad, dedicó todos sus esfuerzos a formar su hacienda.

Dirigió e hizo trabajar tan bien a los indios de su encomienda. que pronto sus viñas le dieron el vino mejor de la comarca. sus campos llenaron de trigo sus bodegas, sus huertos produjeron frutas y hortalizas de todas clases, y sus potreros alimentaban crianzas de animales que tenian renombre de La Serena hasta La Concepción.

Era Don Rodrigo de Aranda persona muy considerada: sus hazañas en las guerras contra los indios eran famosas. y por su justicia y valor habia adquirido una sólida reputación. Don Rodrigo llegó mozo aún a Chile. de modo que su renombre y hazañas de diez años de guerras. lo encontraron joven en toda la lozania de sus 29 años.

La hermosa hacienda de Don Rodrigo estaba situada en Me- 
lipilla, y solamente la abandonaba cuando lo atraia a Santiago algún asunto muy importante para él o para la colonia.

Una mañana llegó a la hacienda de Don Rodrigo el Capilán Oyala. Venia desde Santiago. y explicó a su compañero que su viaje era para llevarlo a Santiago. donde su presencia era indispensable.

Ambos llegaron a Chile al mismo tiempo. habian hecho juntos las campañas. y aunque el Capitán Oyala era más de diez años mayor que Don Rodrigo. los unia la más estrecha amistad.

Sucedia que acababa de llegar a Santiago Doña Josela de la Rueda, esposa de Joan de la Higuera. un vecino de la ciudad. dueño de la mejor pulpería.

Esta dama. por consejo de su marido. habia llegado acompanaada de seis doncellas. (1). Joan de la Higuera. hombre práclico y que de lodo sacaba partido. anunció con tiempo que su mujer llegaria con algunas jövenes (2). que elegirian por esposo entre los encomenderos o vecinos. a aquel que más les agradase o conviniese.

La noticia se esparció con la rapidez del vienlo

Don Joan de la Higuera pasó a ser el hombre de las circunstancias: los Regidores del Cabildo. los Oidores. los encomenderos. lodos empezaron a agasajarlo para que los apadrinara llegado el momento. Cada uno presentaba a porfia sus garantias y riquezas, las lierras y esclavos que tenian. pero ninguno tenía con quién compartirlas, y todos deseaban tener un hogar que les recordara la patria amada y lejana. y les hiciera descansar de la vida de fatigas y conquistas.

Por fin llegaron las esperadas doncellas, y sin largos tramites se desposaron eligiendo entre los que solicitaban sus manos. aquellos que les presentaban más garantias de fortuna y bienestar.

(1). Entre papeles viejos y apolillados existen algunas mercedes olorgadas por el Rey a tal o cual vecino por haber infroducido en el pais: tantas vacas. tanfos ovejas. Iantas damas. efc.... Claudio Gay.

(2). Conserva la historia recuerdo de seis señoritas nobles que trajo una gran dama para proporcionarles estado. - Historia Crítica y Social de la ciudad de Sontiago.-Benjamín Vicuña Mackenna. 
Pero una de ellas. a quien llamaban la Infanzona. hermosa como ninguna mujer que hubiese pisado tierra de indios, se mos. fró desdeñosa $\mathrm{c}$ insolente. Solicitaban su mano un sobrino del Capitán General, un Maestre de Campo. y el Corregidor; cada uno ofrecía al de la Higuera cuanto éstc podía desear: chacra en la Cañada. un gran solar cercado. indios esclavos. fuera de otras gollerias.

El de la Higuera tentado por esas riquezas que despertaban su codicia. temiendo verlas desaparecer. perdió un buen día la paciencia: a pesar de su mujer que le tenía prohibido mezclarse en los asuntos de la Infanzona, conminó a la desdeñosa a elegir entre sus solicitantes un marido. y celebrar sus bodas el próximo domingo; o volver a España en el primer barco que partiera con ese rumbo.

Ante aquella amenaza la Infanzona obedeció. pero puso por condición que solamente en el momento de entrar al pórtico de la Iglesia, elegiría ella a uno de los pretendientes, quienes deberian esperarla y abrirle calle.

Esto fué sembrar pólvora. Se formaron partidos por uno y otro de los pretendientes: se hicieron apuestas: y la paz de la vida colonial fué turbada hasta dentro de los hogares. donde se dividieron las opiniones o se atacaba a la orgullosa dama que llegaba sembrando la discordia.

Don Rodrigo de Aranda escuchó sin interrumpir la narración - de su amigo. y cuando hubo terminado. le dijo:

- ¿Quieren que yo esté presente para impedir que haya una de riñas y duelos entre los que queden desairados?

- Eres el único que puede ser imparcial. porque todos en la ciudad están de parte de uno u otro de los pretendientes: llegado el momento puedes evitar un gran escándalo.

Aquel domingo se hizo estrecho el templo de la Catedral para contener a la inmensidad de fieles que acudian a oir la misa mayor, atraidos por el espectáculo que se les esperaba. 
Mucha gente llenaba la plaza y los alrededores del templo. A la entrada. de pie y luciendo cada cual casaca bordada. espadin y mil aliños de uso y costumbre. estaban el sobrino del Capitán General. el Maestre de Campo. el Corregidor y el Regidor del Cabildo. cada uno en un grupo aparte. rodeado de los suyos: cuando rompiendo los grupos. terciada la capa. afirmada la mano en el puño de la espada. y cubierta la cabeza con el fieltro de larga pluma, llegó Don Rodrigo de Aranda.

Se hizo un silencio, y todos saludaron con respeto al recién llegado. que se adelantó hasta quedar en primer término.

Pocos momentos más tarde, cuando llamaba el sacristán a los fieles, aparecía la linda y codiciada novia, envuelta en su mantilla oscura y crujiendo la basquiña de seda.

Orgullosa-y altiva. seguida de la esposa del de la Higuera. entró la hermosa joven al pórtico. miró a uno y otro lado: sus ojos azules lucian como estrellas bajo el arco perfecto de sus cejas negras y las rizadas pestañas que los rodeaban. Se detuvo un momento. y pálida. con los labios apretados. Entonces, con gran sorpresa de lodos, se avanzó hasta donde estaba el de Aranda. y tendiéndole una mano fina, blanca y ensortijada, le dijo:

- Llevadme al altar.

Era una orden, y aquel hombre acostumbrado a mandar e imponer su voluntad, se inclinó respetuosamente subyugado por la belleza de esa mujer.

Tomando la mano que le tendian. la colocó sobre su brazo. y la pareja atravesó la Catedral seguida por un murmullo de aprobación. hasta el sitio que se le tenía preparado para recibir la bendición nupcial. y oir la misa.

Tras cllos entraron los pretendientes burlados, quienes ponian buena cara a la mala suerte...

\section{III}

Aquel domingo, después del regreso de la Catedral. ya unidos con los lazos del matrimonio. estaban Don Rodrigo de Aranda y la linda joven que sorpresivamente era su esposa. en 
la pequeña sala que servia de comedor en la casa del de la $\mathrm{Hi}$ guera. Sentada en la única silla confortable. la novia exitada. con voz trémula, Jecía al de Aranda que la escuchaba de pie a su lado. con la cabeza inclinada.

-Yo os debo explicaciones... Cuando vi aquellos hombres que me han asediado desde que llegué. comprendi que solamente un milagro podria salvarme de elegir a uno de ellos por esposo: os vi, vuestra persona me era desconocida. pero pareciais el señor de los que os rodeaban. por eso me acerqué a vos, para que me prolegiérais y salvárais

- ¿Pero por qué habéis venido con Doña Josela de la Rueda. y entre las doncellas que la acompañaban?

- ¿Pero no adivináis quién soy? Soy la hija de los duques de Almanza, por mis venas corre sangre de reyes. y por eso me llaman la Infanzona.

La joven se irguió altiva. pero mirando su rededor comprendió que en aquel lugar sus titulos y nobleza no inspiraban más que compasión: entonces con desaliento se dejó caer en su silla. y con roz trémula contó a su esposo su historia.

Allá en un pueblo de Castilla. huérfana desde muy miña. en la regia mansión de sus padres vivia la Infanzona rodeada de dueñas. damas y servidores que se scupaban en darle gusto en sus menores caprichos.

Al morir sus padres la dejaron a cargo de un tio de la niña. pero éste era joven y hermoso. Tavorito de la corte y sólo de tarde en tarde llegaba a visitar a su pupila. Un dia lué acompañado por un vejete contrahecho y ridiculo. pero grande de España, el hombre más rico del reino. Sus visitas aumentaron. hasta que notificó el tio a su sobrina que habia otorgado su mano al gran duque. y que volveria muy pronto para llevarla consigo a la corte donde se bendeciria su boda.

La Infanzona escuchó sin protestar, sabía que era inútil. Pero una vez sola. formó su plan para escapar al destino que le preparaba su tío.

$Y^{\prime}$ una tarde. disfrazada con las ropas de una de sus doncellas salió de su palacio, atravesó el pueblo y llegó a la ca - 
suca de su nodriza quien preparaba su viaje a las indias, para ir a juntarse con su marido. llevando consigo varias jóvenes. Con ruegos y amenazas convenció a su nodriza que la llevará consigo entre el grupo de muchachas. Y entre la nodriza y la niña, arreglaron todo de tal modo. que se creyó en el pueblo que la Infanzona había perecido ahogada: y cuando todos se reunieron para despedir a las viajeras, nadie reconoció en la doncella afligida que lloraba con el rostro oculto en un pañuelo. a la noble Infanzona. hija de los duques de Almanza.

Cuando terminó. las lágrimas ahogaban su voz. y escondiendo el rostro entre las manos dió rienda suelta al llanto contenido durante largas horas.

F.n medio de su aflicción. no vió la joven que su marido salia de la habitación. después de contemplarla con una extraña expresión mezcla de lástima, de cariño y admiración: largo ralo después cuando entró su nodriza a atenderla y consolarla. se sorprendió al saber que el de Aranda después de recomendarla a sus cuidados se había despedido diciéndole que se volvería a su hacienda.

\section{IV}

Cuando don Rodrigo se encontró solo galopando en camino de su hacienda. pudo reflexionar sobre su situación extraña. inverosímil. hasla grolesca.

Estaba casado cuando pocas horas antes no pensaba en el matrimonio; casado, y sin saber de su esposa sino lo que de sus labios oyera: pero lo peor del caso era que aquella Infanzona era linda y encantadora. y él la aceplaba por esposa aunque fuera Infanzona y nieta de reyes.

Pero con la reflexión. el problema se presentaba más difícil cada vez: hasla que don Rodrigo desesperando de resolverlo en la hacienda. montó su caballo el lunes. después de haber descargado su mal genio sobre servidores $y$ esclavos, y por el camino de Santiago llegó al anochecer de aquel dia a la porte- 
ría de San Francisco, en busca de los consejos de su buen amigo el Superior de los Franciscanos.

Sonaba ya la hora de la queda en el esquilón de la Catedral, y aun velaban en el convento el de Aranda y su amigo el franciscano.

En muchos hogares retardaron aquella noche la recogida y el apaga fuego, porque en todos los corrillos de cuadras y estrados se comentaba el curioso matrimonio del domingo.

La noche era tranquila. la luna iluminaba generosainente aquella población coronada por los campanarios de iglesias y conventos. encerrada entre los altos muros de los solares, y perfumada por las huertas y chácaras de la Cañada.

De repente. sin aviso alguno, un horroroso sacudón de tierra que duró largos minutos desplomó torres. techos y muros en una horrible confusión; la luz de la luna se nubló con el polvo levantado por las murallas que caían; un clamor de angustia, queja dolorida de la población. siguió al silencio.

De un salto el de Aranda se encontró fuera de la sala. y a pesar de los muros que caian. de los techos que se derrumbaban. a través de corredores y jardines. llegó a la Cañada y se internó por las calles, donde todo era confusión, lamentos $y$ ruina.

En la pulpería de Joan de la Higuera conversaban en la estancia que conocemos. la Infanzona, la nodriza y su marido. Este refería a la joven detalles de las hazañas del de Aranda. La joven escuchaba y preguntaba con interés, cuando de pronto llegó aquel horroroso sacudón que destruyó la ciudad entera en algunos minutos.

La Infanzona llevada por el terror se encontró en medio de la calle sin darse cuenta. vió derrumbarse los muros y caer los techos, su voz se unió al clamor general de los que escaparon con vida. Sola en medio de la calle, rodeada de horrores y muerta de miedo. la pobre niña llamaba a su padre. a su nodriza y lloraba desconsolada.

En esos momentos se le acercó una persona quien le habló con ternura. la tranquilizó y ella tomándole un brazo le dijo: 
¡Mi nodriza está alli dentro, sálvela!

Inmediatamente el de Aranda a quien la joven no reconoció. se introdujo con peligro de su vida entre las paredes que se derrumbaban y las vigas qne caian: a poco apareció con la nodriza entre sus brazos. la que presentaba una gran herida en la cabeza.

Dejó a la nodriza a los pies de su esposa. y volvió a entrar en busca del de la Higuera, a quien también sacó casi muerto. Una vez que los dos heridos fueron atendidos lo mejor que se pudo. Don Rodrigo ayudado siempre por la joven los llevó hasta el pie de un árbol; poco después empezó a llover copiosamente. y el joven envolvió a la Infanzona en su amplia capa, y allí bajo el árbol que apenas los defendia del agua. atendiendo a los heridos esperaron el día cambiando de vez en cuando algunas palabras.

Cuando las primeras luces del dia permitieron ver claro. la Infanzona reconoció quien era su salvador. y tendiéndole una mano le dijo:

- Gracias, vos teníais que ser...!

Don Rodrigo dejó a su esposa con los heridos mientras iba a buscar en qué llevarlos a un sitio seguro. Volvió más tarde en su caballo, acompañando una carreta tirada por bueyes y guiada por un indio; alli entre la paja pusieron a los heridos. y Don Rodrigo hizo subir a su mujer acomodándola lo mejor posible: cuando todo estuvo pronto. dió orden al indio de ponerse en inarcha.

Lentamente alravesaron la población en ruinas. cruzando entre escenas de desolación. muerte y lágrimas, porque el terremoto del 13 de Mayo desplomó la ciudad entera. enterrando bajo sus escombros a la mitad de sus habitantes.

La carreta salió al campo dejando tras sí el dolor y las lágrimas, y se dirigió hacia la hacienda de Don Rodrigo.

$\mathrm{Y}$ asi como aquel temblor de Mayo, como se le llamó en ese entonces. destrozó tantos hogares y destruyó tantas vidas. sirvió también para formar un nuevo hogar y unir dos vidas con el más perfecto cariño. 